\title{
BMJ Open Long-term exposure to particulate air pollution and black carbon in relation to natural and cause-specific mortality: a multicohort study in Sweden
}

\author{
Johan Nilsson Sommar (D) , ${ }^{1}$ Eva M Andersson, ${ }^{2}$ Niklas Andersson, ${ }^{3}$ Gerd Sallsten, ${ }^{2}$ \\ Leonard Stockfelt, ${ }^{2}$ Petter LS Ljungman, ${ }^{3,4}$ David Segersson, ${ }^{5}$ Kristina Eneroth, ${ }^{6}$ \\ Lars Gidhagen, ${ }^{5}$ Peter Molnar, ${ }^{2}$ Patrik Wennberg, ${ }^{7}$ Annika Rosengren, ${ }^{8}$ \\ Debora Rizzuto, ${ }^{9,10}$ Karin Leander, ${ }^{3}$ Anton Lager, ${ }^{11,12}$ Patrik KE Magnusson, ${ }^{13}$ \\ Christer Johansson, ${ }^{6,14}$ Lars Barregard, ${ }^{2}$ Tom Bellander, ${ }^{3,15}$ Göran Pershagen, ${ }^{3,15}$ \\ Bertil Forsberg ${ }^{1}$
}

To cite: Nilsson Sommar J, Andersson EM, Andersson N, et al. Long-term exposure to particulate air pollution and black carbon in relation to natural and cause-specific mortality: a multicohort study in Sweden. BMJ Open 2021;11:e046040. doi:10.1136/ bmjopen-2020-046040

\section{- Prepublication history and} additional supplemental material for this paper are available online. To view these files, please visit the journal online (http://dx.doi.org/10.1136/ bmjopen-2020-046040)

Received 19 0ctober 2020 Accepted 07 August 2021

Check for updates

(C) Author(s) (or their employer(s)) 2021. Re-use permitted under CC BY. Published by BMJ.

For numbered affiliations see end of article.

Correspondence to Dr Johan Nilsson Sommar; johan.sommar@umu.se

\section{ABSTRACT}

Objectives To estimate concentration-response relationships for particulate matter (PM) and black carbon (BC) in relation to mortality in cohorts from three Swedish cities with comparatively low pollutant levels.

Setting Cohorts from Gothenburg, Stockholm and Umeå, Sweden.

Design High-resolution dispersion models were used to estimate annual mean concentrations of PM with aerodynamic diameter $\leq 10 \mu \mathrm{m}$ (PM10) and $\leq 2.5 \mu \mathrm{m}$ (PM2.5), and BC, at individual addresses during each year of follow-up, 1990-2011. Moving averages were calculated for the time windows $1-5$ years (lag1-5) and 6-10 years (lag6-10) preceding the outcome. Causespecific mortality data were obtained from the national cause of death registry. Cohort-specific HRs were estimated using Cox regression models and then metaanalysed including a random effect of cohort.

Participants During the study period, 7340 cases of natural mortality, 2755 cases of cardiovascular disease (CVD) mortality and 817 cases of respiratory and lung cancer mortality were observed among in total 68679 individuals and 689813 person-years of follow-up. Results Both PM10 (range: $6.3-41.9 \mu \mathrm{g} / \mathrm{m}^{3}$ ) and BC (range: $0.2-6.8 \mu \mathrm{g} / \mathrm{m}^{3}$ ) were associated with natural mortality showing $17 \%(95 \% \mathrm{Cl} 6 \%$ to $31 \%)$ and $9 \%(95 \%$ $\mathrm{Cl} 0 \%$ to $18 \%$ ) increased risks per $10 \mu \mathrm{g} / \mathrm{m}^{3}$ and $1 \mu \mathrm{g} / \mathrm{m}^{3}$ of lag1-5 exposure, respectively. For PM2.5 (range: $4.0-$ $\left.22.4 \mu \mathrm{g} / \mathrm{m}^{3}\right)$, the estimated increase was $13 \%$ per $5 \mu \mathrm{g} / \mathrm{m}^{3}$, but less precise $(95 \% \mathrm{Cl}-9 \%$ to $40 \%)$. Estimates for CVD mortality appeared higher for both PM10 and PM2.5. No association was observed with respiratory mortality. Conclusion The results support an effect of long-term air pollution on natural mortality and mortality in CVD with high relative risks also at low exposure levels. These findings are relevant for future decisions concerning air quality policies.

\section{INTRODUCTION}

Particulate matter (PM) ambient air pollution exposure has been associated with increased risk of premature mortality in several cohort

\section{STRENGTHS AND LIMITATIONS OF THIS STUDY}

$\Rightarrow$ Few previous studies have followed up individuals by home address and time-varying exposures as annual mean concentrations at actual place of residence.

$\Rightarrow$ High-resolution dispersion models of particle concentrations were used to capture local contrasts in exposure.

$\Rightarrow$ The study did, however, not include information on noise exposure and green space near the home address.

$\Rightarrow$ This study showed associations with mortality within populations with comparatively low particle concentrations, generally below European Union standards.

$\Rightarrow$ As the first (multi)cohort study using high-resolution dispersion modelled particle concentrations at mean levels below WHO guidelines, this study found high relative risks of mortality.

studies. ${ }^{12}$ According to the Global Burden of Diseases Study 2017, ${ }^{3}$ assessing 84 risk factors for premature mortality in 195 countries, ambient PM air pollution was ranked as the tenth most important risk factor for mortality and the most important environmental risk factor. Using risk functions restricted to cohort studies of outdoor air pollution, ambient particle matter pollution was estimated to cause 2.9 million (95\% CI 2.5 to 3.4 ) deaths in year 2017.

In a review of 11 cohort studies on longterm air pollution exposure and mortality, ambient concentrations of PM with aerodynamic diameter $\leq 2.5 \mu \mathrm{m}$ (PM2.5) were associated with increased risk of all-cause mortality and particularly cardiovascular mortality. However, the heterogeneity between study 
relative risk estimates was large. ${ }^{2}$ The large European Study of Cohorts for Air Pollution Effects (ESCAPE) project including 22 cohorts, observed an increased risk of overall mortality associated with ambient PM2.5 concentrations ${ }^{4}$ whereas no association was found with cardiovascular mortality. ${ }^{5}$ In a recent study within a large Danish cohort found increased risks for both natural cause and cardiovascular disease (CVD) mortality associated with PM2.5 exposure during the last 15 years. ${ }^{6}$ Neither the Danish study nor the ESCAPE study was able to demonstrate associations with respiratory mortality. ${ }^{67}$

Black carbon (BC), one component of PM, has been hypothesised to play a key role in the adverse health effects of air pollution exposure. ${ }^{8}$ The review by Luben $e t$ $a l$ identified three studies on the long-term effect of BC (or elemental carbon) and mortality in coronary heart disease $^{9}$ and ischaemic heart disease. ${ }^{10}{ }^{11}$ However, the review did not find support for a stronger association with mortality for BC compared with PM2.5. Elemental carbon has been associated with all-cause mortality in another meta-analysis. ${ }^{2}$ Within the ESCAPE project, PM2.5-absorbance was used as a proxy for BC. The estimated increased risk of natural mortality associated with PM2.5-absorbance did not reach statistical significance. ${ }^{4}$ In Denmark (areas of Copenhagen and Aarhus), BC was, however, associated with both all-cause and cardiovascular mortality. ${ }^{6}$

These previous studies varied in the method used for the exposure assessment of particle concentrations. Earlier studies assessed concentrations using centrally located monitoring stations, mostly representing the urban background. ${ }^{12}$ Later studies use air pollution monitoring together with data on land use (LUR) or detailed data on emissions and meteorological conditions (dispersion models). Most studies on long-term air pollution effects have assessed outdoor residential exposures at the year of inclusion into the cohort, a recent study on mortality however used annual mean concentrations on addresses during follow-up. ${ }^{6}$ Studies using exposure assessments with a higher precision and in low-level exposure environments demonstrated higher relative risks of mortality in a recent meta-analysis. ${ }^{13}$ Studies on low level air pollution are few, however. Adding to the knowledge from the longterm air pollution effects on mortality from the Canadian Community Health Survey-Mortality cohort $^{14-16}$ and a Medicare population in New England, ${ }^{17}$ this study is of importance for policy making and determination of limit values. Compared with these previous studies that used a $1 \times 1 \mathrm{~km}^{2}$ resolution for the assessment of air pollutant concentrations this study will make use of high-resolution $50 \times 50 \mathrm{~m}^{2}$ dispersion modelled PM able to capture also local exposure contrasts.

\section{AIM}

This study aims to use high-resolution dispersion modelled annual mean residential PM10, PM2.5 and BC concentrations to estimate associations with natural and cause-specific mortality in a northern European environment characterised by annual averages largely compliant with European Union (EU) air quality standards.

\section{METHODS AND MATERIALS}

\section{Study cohorts}

The study included four cohorts; two cohorts from Gothenburg, one from Stockholm (pooled from four cohorts) and one cohort from Umeå. Our study period ranged from 1 January 1990 to 31 December 2011 (31 December 2013 for Umeå participants residing at the same address as in 2011). Residential address history was obtained for all cohort participants through linkage using personal identification numbers to mandatory records of residential addresses at Statistics Sweden or the Swedish Taxation Authority. These residential addresses were then geocoded by matching against the Swedish Mapping Cadastral and Land Registration Authority databases. When needed, addresses were manually checked and corrected for inconsistencies and assigned geographical coordinates.

From Gothenburg, two general population cohorts were included: The Primary Prevention Study (PPS) cohort and the Multinational Monitoring of Trends and Determinants in Cardiovascular Diseases (GOT-MONICA) cohort. The PPS cohort recruited a random third of all men in Gothenburg born between the years 1915 and 1925 who were examined in 1970-1973 to study predictors of CVD. ${ }^{18}$ The GOT-MONICA cohort is one of the cohorts within the international MONICA project designed to study risk factors for CVDs. ${ }^{19}{ }^{20}$ GOT-MONICA included residents aged 25-64 years. Recruitments were conducted in 1985, 1990 and 1995. For both cohorts, background data and information on cardiovascular risk factors were recorded by questionnaires. The recruited individuals were also examined by healthcare professionals.

Recruiting individuals from Stockholm County the Cardiovascular Effects of Air pollution and Noise Study (CEANS) cohort was included. ${ }^{21}$ The cohort consists of four subcohorts. The Stockholm Diabetes Prevention Programme (SDPP) was designed as a population-based prospective cohort, and includes 3128 men recruited between the years 1992 and 1994 and 4821women recruited between the years 1996 and 1998. The programme recruited individuals aged 35-56 years that had not previously been diagnosed with diabetes. About half of the recruited had a first or second degree relative with a history of diabetes. These were then matched with recruits of the same age and sex, who did not have a relative with a diabetes history. The second subcohort named SIXTY consists of a population-based random sample of 60-year-old men and women ( $\mathrm{N}=4$ 232) living within Stockholm County between August 1997 and March 1999. The third cohort consists of the Screening Across the Lifespan Twin study, including twins born before year 1958. Only participants residing in Stockholm County at recruitment were included in the current analysis $(\mathrm{N}=7$ 
043). The fourth subcohort, the Swedish National Study on Aging and Care in Kungsholmen, included a random sample of inhabitants aged at least 60 years and residing in a central area of Stockholm City ( $\mathrm{N}=3$ 363). Subcohortspecific characteristics of included individuals in CEANS have previously been presented. ${ }^{22}$

Including Umeå municipality, the Västerbotten Intervention Programme (VIP) is a programme where the population in the county is invited to a health examination the year they turn 40,50 and 60 (and during some years also 30 ) years old. ${ }^{23}$ The programme was initiated in parts of the county in 1985 as a community-level and individual-level programme to reduce the morbidity and mortality from CVD in Northern Sweden. The interview questions provide information about cardiovascular risk factors as well as social situation, education, diet and physical activity. So far more than 100000 individuals have participated in the programme.

\section{Patient and public involvement}

No patient involved. The public was also not involved in the design, or conduct, or reporting, or dissemination plans of the research.

\section{Mortality outcomes}

Cause-specific mortality was determined by linkage of national personal identification numbers to the Cause of Death Register at the Swedish National Board of Health and Welfare. We used the International Code of Diseases (ICD)-9 001-779 or ICD-10 A00-R99 to define deaths by natural causes, ICD-9 400-440 or ICD-10 I10-I70 to define deaths in CVD, ICD9 162 or ICD10 C34 to define lung cancer deaths, and ICD9 460-519 or ICD10 J0-99 to define non-malignant respiratory mortality. In addition, deaths by other causes was studied (that is other than CVD, lung cancer, respiratory disease and external causes).

\section{Exposure assessment}

An in-depth description of the dispersion model used for the exposure assessment has previously been published. ${ }^{24}$ Both regional and local emission inventories for the years 1990, 2000 and 2011 in Gothenburg and Umeå, and years 1990, 1995, 2000, 2005 and 2011 in Stockholm, were used as input to Gaussian dispersion model simulations of annual mean concentrations of PM, that is, PM with aerodynamic diameter $\leq 10 \mu \mathrm{m}$ (PM10), PM2.5 and BC. To allow high resolution in vicinity of roads, a quadtree receptor grid was used, resulting in a resolution down to $35 \mathrm{~m}$ x $35 \mathrm{~m}$. For inner-city streets with buildings on one or both sides, an additional concentration component was simulated with the Danish operational street pollution model. ${ }^{25}$

Monitoring data were used in Stockholm to adjust the modelled concentrations to meteorological year-to-year variability. In Gothenburg and Umeå, interpolation was used between the years and each year was also adjusted by a ventilation factor taking meteorological variability into account. Emission factors for traffic PM-exhaust for different vehicle types, speeds and driving conditions were calculated based on the Handbook on Emission Factors for Road Traffic V.3.1 ${ }^{26}$ whereas emission factors for BC were based on TRANSPHORM. ${ }^{27}$ The non-exhaust emissions of PM consist mainly of road wear particles, with a minor contribution from brake and tire wear. ${ }^{28-30}$ For small-scale residential heating, emissions in Gothenburg and Stockholm were determined using household energy consumption data from Statistics Sweden with a resolution of $100 \times 100$ $\mathrm{m}$. This was based on proxy data including number of stoves or boilers in each municipality, living space of small houses per square $\mathrm{km}$, population density per $100 \mathrm{~m}^{2}$ and availability of district heating. In Umeå a detailed inventory of individual stoves and boilers was used with data from chimney sweepers and interviews about amount of wood burning. ${ }^{24}$ Industrial and energy production facilities were included as point sources in the model. Emission from shipping was also included using a method described by Jalkanen et al. ${ }^{31}$

To model the long-range transport of PM10, PM2.5 and $\mathrm{BC}$ the difference between total concentrations measured at monitoring stations and modelled local particle concentrations at the same location was considered on an annual basis (Gothenburg and Umeå). In Stockholm annual concentrations from a regional background station was used to estimate the long-range transport. The long-range transport contributions were estimated differently for each city, but within each city they had a purely temporal contrast. This was assumed since the spatial variation between regional background sites has been shown to be small. ${ }^{32}$ These yearly contributions of background concentrations were then added to the estimated local concentrations. In a previous study, validations of total concentrations against measurements showed $\mathrm{R}^{2}$ values of $0.87,0.65$ and 0.93 for PM10, PM2.5 and $\mathrm{BC}$, respectively. ${ }^{24}$

The resulting concentrations were lastly added to each study participant's home addresses and annual exposures estimated accounting for any changes in address during the study period 1990-2011.

\section{Confounders}

Cohort-specific models were adjusted for potential confounding by including sex, calendar year, subcohort (in Stockholm), smoking status (current, former, never smoker), alcohol consumption (in Stockholm and Umeå; daily, weekly, seldom, never), physical activity (in Gothenburg and Umeå: sedentary, moderate, intermediate or vigorous; in Stockholm: once a month or less $/>1$ hour per week, about once a month $/ 1$ hour per week, 3 times a week or more/ $>2$ hours per week), marital status (single, married or living with partner, no answer), socioeconomic index by occupation (in Gothenburg (PPS) and Stockholm: blue collar, low and intermediate white collar and self-employed, high level white collar and self-employed professionals 
with academic degrees, no answer), education level (in Gothenburg (MONICA), Stockholm and Umeå: primary school or less, up to secondary school or equivalent, university degree or more, no answer), occupation status (in Stockholm and Umeå: gainfully employed, unemployed/not gainfully employed, retired, no answer). Area-level socioeconomic status was estimated for each cohort member's residence from the mean neighbourhood individual income in persons of working age by Small Areas for Market Statistics provided by Statistics Sweden for the calendar year 1994.

\section{Statistical methods}

Cox proportional hazard models were used to estimate HRs of mortality associated with PM and BC in cohortspecific analyses. Age was used as the underlying time variable for the baseline hazard. The regression model included adjustment for calendar year, baseline information on confounders as well as area-level socioeconomic. Since the Stockholm CEANS cohort consisted of four subcohorts that differed in age and time of recruitment, separate baseline hazards were used for the analyses within this cohort. We censured individuals at death by other causes, the end of the study period or time of permanent emigration from the study areas. Associations with $\mathrm{PM}$ and $\mathrm{BC}$ were assessed using two exposure windows; a moving average over 1-5 years preceding the event (lag1-5) and 6-10 years preceding the event (lag6-10). For inclusion, annual mean concentrations were required for at least $80 \%$ of the time window. These moving averages were used as time-varying exposures and therefore considers both between and within individual contrast during the study period. Besides these time windows, associations were also assessed with concentrations at the year of recruitment. HRs and $95 \%$ CIs were expressed per 10,5 and $1 \mu \mathrm{g} / \mathrm{m}^{3}$ for PM10, PM2.5 and $\mathrm{BC}$, respectively, as well as per IQRs across the three study areas.

Meta-analyses of cohort-specific estimates were performed using random effects. ${ }^{33}$ Heterogeneity between cohort estimates were assessed by the $\mathrm{I}^{2}$ statistic and statistically tested for deviations from homogeneity by a $\chi^{2}$ test based on the Cochran's $Q$ statistic.

\section{RESULTS}

\section{Participant characteristics}

The total number of individuals included in our metaanalysis was 68679 , with the number of individuals included in each cohort presented in table 1 . Total number of deaths by natural causes was 7344 . Age at recruitment differed largely between cohorts with the highest median in the Gothenburg PPS cohort and lowest in VIP Umeå, 69 compared with 40 years. By design only males were recruited to the Gothenburg PPS cohort, whereas the other three cohorts had a slightly larger proportion of women compared with men. Baseline current smoking was highest in the Gothenburg PPS cohort and lowest in Stockholm CEANS and VIP Umeå, 39\% compared with about $20 \%$. Leisure time physical activity had a different categorisation within the Stockholm CEANS cohort but it can be concluded that there was a larger proportion of individuals reporting a sedentary lifestyle at baseline in this cohort. The cohorts in Gothenburg had the largest proportion of physically active individuals, with higher frequency and intensity. Alcohol consumption was more frequent in Stockholm CEANS compared with VIP Umeå. University education was most common in Stockholm CEANS and VIP Umeå (above 30\%) and less common in Gothenburg. A larger proportion of individuals were gainfully employed in the younger VIP Umeå than in Stockholm CEANS, 84\% compared with 66\%. Blue-collar occupation was more likely within the Gothenburg PPS cohort compared with Stockholm CEANS.

\section{Particle concentrations}

Particle concentrations of PM10, PM2.5 and BC all had the highest mean and IQR in the Gothenburg cohorts and the lowest in VIP Umeå (figures 1-3). In total, means of lag1-5 PM10, PM2.5 and BC were; 11.3, 6.9 and $0.6 \mu \mathrm{g} /$ $\mathrm{m}^{3}$, respectively. Lag1-5 concentrations were on average lower than lag6-10 concentrations due to a decreasing trend in concentrations during the study period. The Pearson correlation coefficient between lag 1-5 concentrations of PM10 and PM2.5 was 0.88, PM10 and BC 0.71, and between PM2.5 and BC 0.75.

\section{Associations with mortality}

Meta-estimates showed increased risks associated with PM10, PM2.5 and BC in relation to natural mortality; for lag $1-517 \%$ (95\% CI $6 \%$ to $31 \%$ ) increased risk per $10 \mu \mathrm{g} / \mathrm{m}^{3} \mathrm{PM} 10,13 \%$ (95\% CI $-9 \%$ to $40 \%$ ) increased risk per $5 \mu \mathrm{g} / \mathrm{m}^{3}$ PM2.5 and $9 \%$ (95\% CI $0 \%$ to $18 \%$ ) increased risk per $1 \mu \mathrm{g} / \mathrm{m}^{3} \mathrm{BC}$ (figures $4-6$; crude estimates in online supplemental material figure S1A-C). The statistical uncertainty was however considerable for the combined risk increase associated with PM2.5 and the CI included 1. For PM10 and PM2.5 higher risk estimates were found for lag1-5 concentrations compared with lag6-10, whereas for $\mathrm{BC}$, the risk estimates were the same. Increased risks were estimated for all cohorts except for Gothenburg MONICA, where the HR estimate for natural mortality was below 1 .

The risk estimates for CVD mortality associated with PM10 and PM2.5 appeared higher compared with natural mortality; $19 \%$ (95\% CI $1 \%$ to $40 \%$ ) and $23 \%$ (95\% CI $3 \%$ to $48 \%$ ) increased risks for lag1-5, per 10 and $5 \mu \mathrm{g} /$ $\mathrm{m}^{3}$, respectively (figures 7-9; crude estimates in online supplemental material figures S2A-B). The increased risks associated with BC seemed lower for CVD mortality than for natural mortality for lag1-5, but similar for lag6-10 (figure 9; crude estimates in online supplemental material figure $\mathrm{S} 2 \mathrm{C}$ ).

The HRs per IQR for natural mortality were higher for PM2.5 and PM10 than for BC; 6\%, 5\% and 2\% increased 
Table 1 Descriptive statistics of the study participants in each cohort

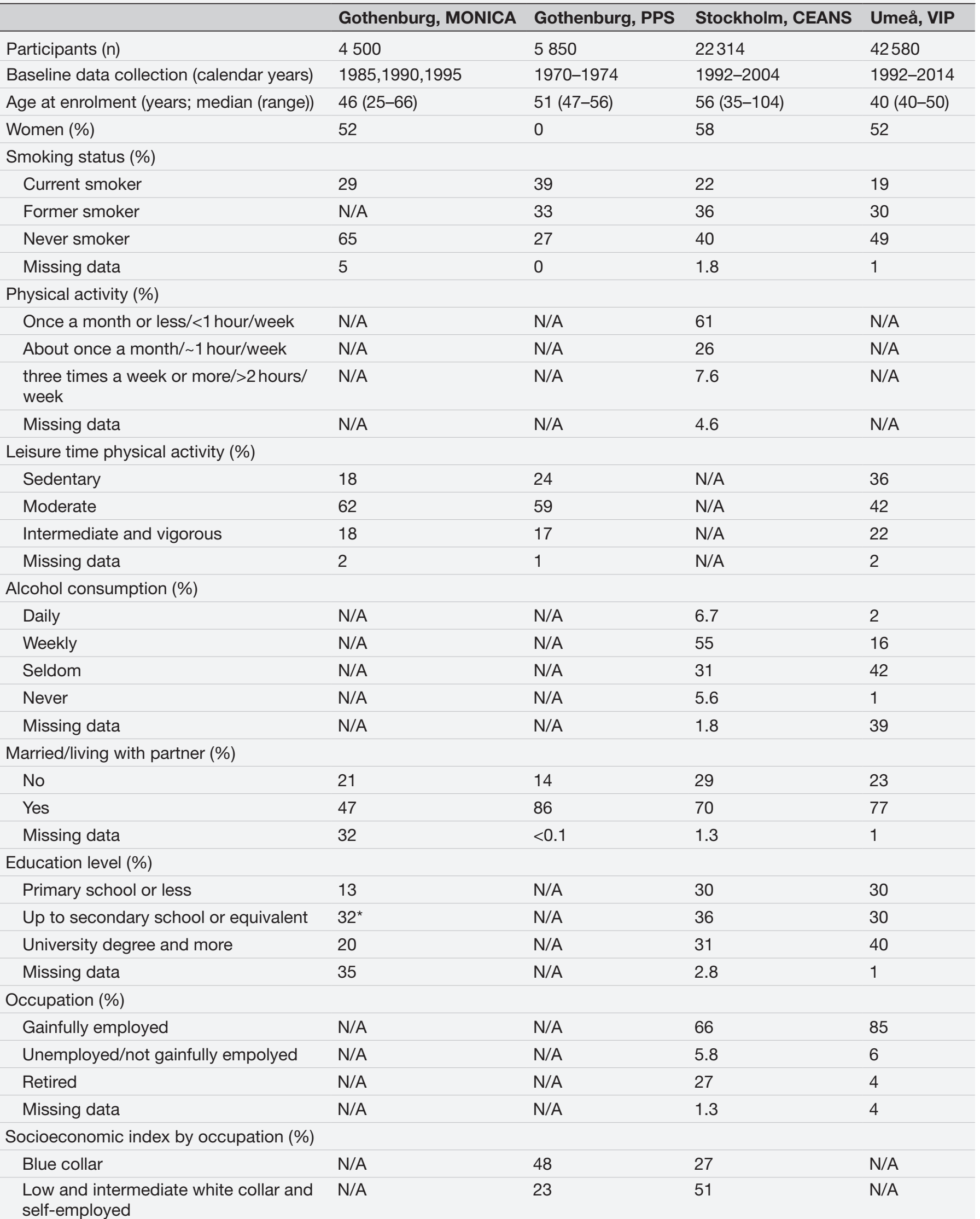


Table 1 Continued

\begin{tabular}{|c|c|c|c|c|}
\hline & Gothenburg, MONICA & Gothenburg, PPS & Stockholm, CEANS & Umeå, VIP \\
\hline Missing data & N/A & 0 & 4.4 & N/A \\
\hline Mean income by SAMS 1994 (SEK) & 154780 & 148602 & $\mathrm{~N} / \mathrm{A}$ & 130000 \\
\hline
\end{tabular}

risk, respectively. The same order per IQR was found for CVD mortality; $10 \%, 5 \%$ and $1 \%$ for PM2.5, PM10 and $\mathrm{BC}$, respectively.

No associations between PM and lung cancer or nonmalignant respiratory mortality were observed (online supplemental material figures S3A-C and S4A-C). Increased risk was, however, observed for mortality by other causes (that is other than CVD, lung cancer, respiratory disease and external causes) with the same magnitude as observed for natural and CVD mortality (online supplemental material figures $\mathrm{S} 5 \mathrm{~A}-\mathrm{C}$ ).

For comparison with previous studies, associations were also assessed with residential PM concentrations for the recruitment year. These estimates were in general lower compared with those with lag1-5 and lag6-10 concentrations (online supplemental material figures S6A-B). Estimated risk increases for natural mortality were $7 \%(95 \%$ CI $-4 \%$ to $18 \%), 8 \%(95 \%$ CI $-2 \%$ to $20 \%)$ and $3 \%(95 \%$ CI $-4 \%$ to $11 \%$ ) in association with PM10, PM2.5 and BC, per 10,5 and $1 \mu \mathrm{g} / \mathrm{m}^{3}$, respectively.
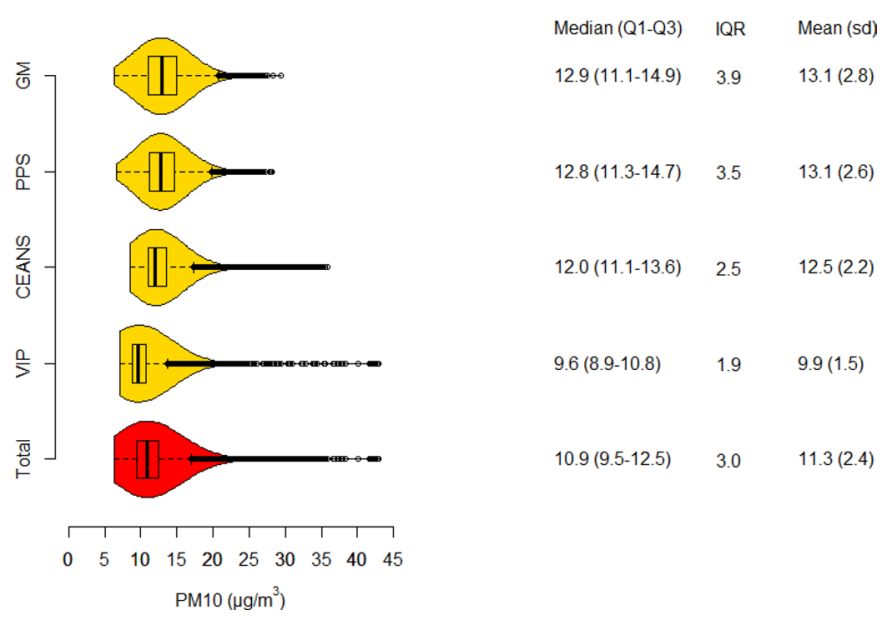

Figure 1 Boxplot and density function of PM10 concentrations, in total and separate for each cohort. Tabulated values are quartile limits together with means and SD. CEANS, Cardiovascular Effects of Air Pollution and Noise Study; MONICA, Multinational Monitoring of Trends and Determinants in Cardiovascular Diseases; PM, particulate matter; PPS, Primary Prevention Study; VIP, Västerbotten Intervention Programme.
The heterogeneity between cohort HR estimates in relation to precision was in general very low. Heterogeneity was, however, observed for associations with lag1-5 PM2.5 and lag6-10 BC in relation to natural mortality, although non-of these were statistically significant (figures 4-9).

\section{DISCUSSION}

We observed in four Swedish cohorts located in Gothenburg, Stockholm and Umeå increased risks associated with long-term residential outdoor levels of PM10, PM2.5 and BC in relation to natural and CVD mortality. PM10 was most consistently associated with natural and CVD mortality, whereas larger uncertainties were found for the associations between PM2.5 and CVD mortality and BC and natural mortality. Risk estimates associated with PM10 and PM2.5 appeared larger for exposures during the last 5 years in comparison to $6-10$ years prior. For $\mathrm{BC}$ the associated risks

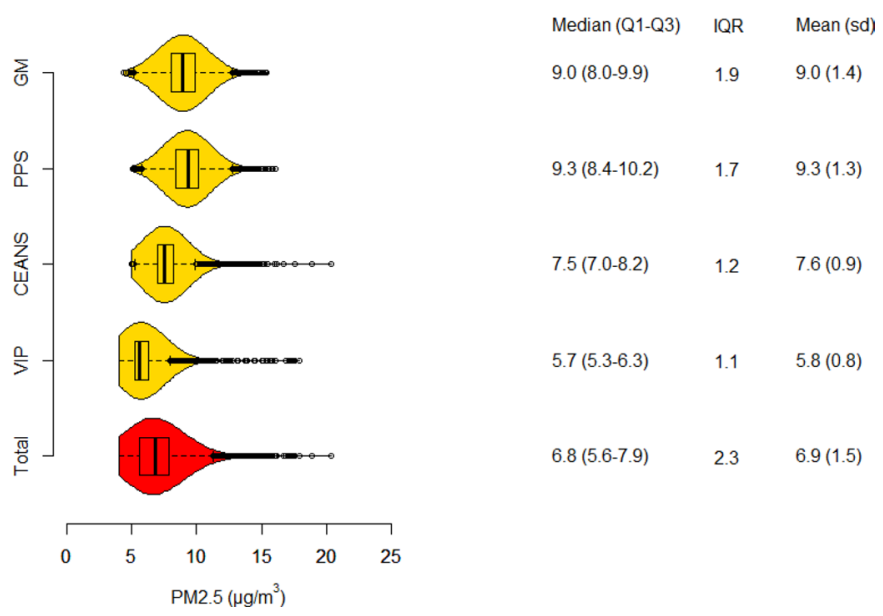

Figure 2 Boxplot and density function of PM2.5 concentrations, in total and separate for each cohort. Tabulated values are quartile limits together with means and SD. CEANS, Cardiovascular Effects of Air Pollution and Noise Study; MONICA, Multinational Monitoring of Trends and Determinants in Cardiovascular Diseases; PM, particulate matter; PPS, Primary Prevention Study; VIP, Västerbotten Intervention Programme. 


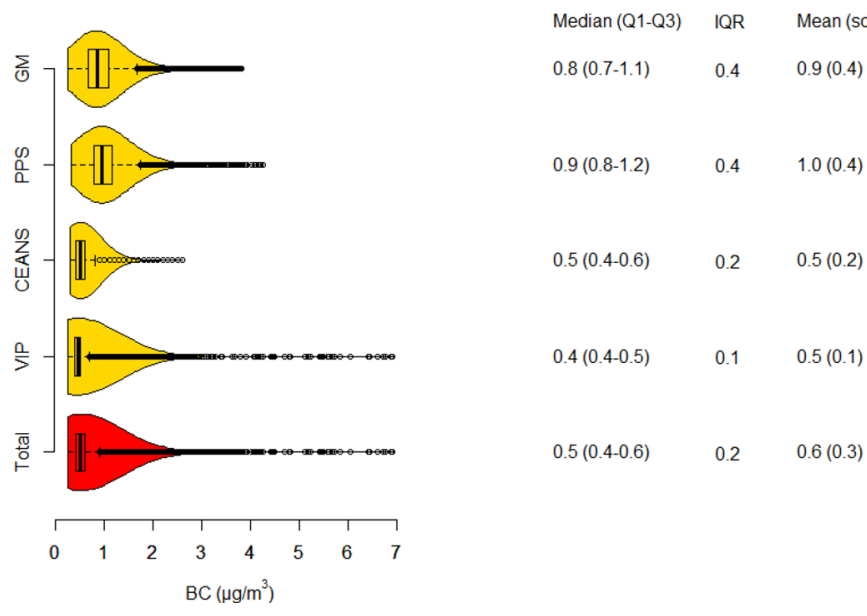

Figure 3 Boxplot and density function of BC concentrations, in total and separate for each cohort. Tabulated values are quartile limits together with means and SD. BC, black carbon; CEANS, Cardiovascular Effects of Air Pollution and Noise Study; MONICA, Multinational Monitoring of Trends and Determinants in Cardiovascular Diseases; PPS, Primary Prevention Study; VIP, Västerbotten Intervention Programme.

were the same for both exposure windows in relation to natural mortality but higher for the exposure window 6-10 years prior in relation to CVD mortality. Within a previous meta-analysis of these cohorts, an association was found between BC and stroke incidence. ${ }^{22}$ No association was, however, found between PM10 or PM2.5 and incidence in ischaemic heart disease.

The observed $17 \%$ increased risk per $10 \mu \mathrm{g} / \mathrm{m}^{3}$ PM10 in relation to natural mortality is high compared with most studies (eg, the $6 \%$ increased risk found by Hoek et $a l^{2}$ but similar to the recent findings within a Danish cohort presenting $12 \%$ increased risk (95\% CI $3 \%$ to $22 \%$ ) associated with a 15-year moving average of residential ambient concentrations. ${ }^{6}$ Their estimate for CVD mortality was $30 \%$ (95\% CI $11 \%$ to $53 \%$ ) which was higher than our meta-estimate of $19 \%$. For PM2.5 our observed risk increase by $13 \%$ per $5 \mu \mathrm{g} / \mathrm{m}^{3}$ for natural mortality is also in agreement with the Danish estimate of $13 \%$ (95 CI 5\% to 21\%). As for PM10 the risk increase for CVD mortality associated with PM2.5 was again lower in our study, 23\% compared with $29 \%$ (95\% CI $13 \%$ to $47 \%$ ). The average PM10 and PM2.5 exposure levels were 2.2 and 2.6 times higher in the Danish cohort compared with our study (lag1-10 time-weighted concentrations from the Danish cohort compared with lag1-5 moving averages in our study).

Using less detailed assessments of outdoor residential exposures, a meta-analysis of 22 cohorts within the ESCAPE project reported a borderline significant $4 \%$ (95\% CI $0 \%$ to $9 \%$ ) increased risk of natural-cause mortality for a $10 \mu \mathrm{g} / \mathrm{m}^{3}$ difference in annual PM10 at the year of recruitment. ${ }^{4}$ No association with PM10 was, however, observed for deaths in ischaemic heart disease or myocardial infarction, whereas a suggested association was found in relation to deaths in cerebrovascular disease; $22 \%$ (95\% CI $-9 \%$ to $63 \%$ ) increased risk per 10 $\mathrm{\mu g} / \mathrm{m}^{3.5}$ The findings for mortality associated with PM2.5 have been heterogeneous, however, the meta-estimate among the ESCAPE cohorts showed a $7 \%$ (95\% CI 2\% to $13 \%$ ) increased risk per $5 \mu \mathrm{g} / \mathrm{m}^{3}$ of natural mortality and $21 \%$ (95\% CI $-13 \%$ to $69 \%$ ) increased risk of death in cerebrovascular disease. As for PM10 no association was found in relation to death in ischaemic heart disease or myocardial infarction. Within earlier studies; a review and meta-analysis by Hoek et al found 6\% (95\% CI $4 \%$ to $8 \%$ ) and $15 \%$ (95\% CI $4 \%$ to $27 \%$ ) increased risks of all-cause mortality and cardiovascular mortality per $5 \mu \mathrm{g} /$ $\mathrm{m}^{3}$, respectively. A stronger association between PM and mortality with cardiovascular causes compared with all natural mortality has also been reported by others, ${ }^{1}$ and is in agreement with our findings on CVD mortality; and most apparent in relation to exposures during the last 5 years.

In accordance with our meta-estimate for BC the Danish cohort reported a risk increase by $9 \%(95 \%$ CI $4 \%$ to $15 \%$ ) per $1 \mu \mathrm{g} / \mathrm{m} 3$ for all-cause mortality. ${ }^{6}$ An increased risk by $16 \%$ (95\% CI $5 \%$ to $27 \%)$ was also observed for CVD mortality, higher than the $5 \%$ increased risk found in our study. In the review by Hoek et al elemental carbon was found associated with a $6 \%(95 \%$ CI $5 \%$ to $7 \%)$ increased risk of all-cause mortality per $1 \mu \mathrm{g} / \mathrm{m}^{3}$.

The lack of association between PM and non-malignant respiratory mortality in our study is in agreement with results from both the Danish study, ${ }^{6}$ the ESCAPE study ${ }^{7}$ and a large cohort study in Rome. ${ }^{34}$ Previous studies have, however, found an increased risk of lung cancer incidence associated with both PM10 and PM2.5. ${ }^{35}$ The statistical power for these outcomes was low in our meta-analyses due to the limited number of deaths in lung cancer and other respiratory causes.

The observed heterogeneity of PM associated risk for premature mortality between studies is possibly related to differences in particle composition, housing with differences in particle infiltration, population characteristics and the minor differences in confounding adjustments. The air pollution dispersion model used for the exposure assessment in our study has a high spatial resolution, and for the follow-up period it was also updated with new regional and local emission inventories as well as PM measurements to provide annual mean temporal PM concentrations. A higher precision in the exposure estimate have been found to produce higher relative health risk estimates. ${ }^{13}$ The mortality risk associated with PM2.5 has recently been reported to be higher for local sources compared with distant sources, but with less precision in relative risk estimates, indicating the importance of high spatial resolution exposure data to successfully model differences in mortality. ${ }^{37}$ The metaanalysis results in this study and the results presented by Hvidtfeldt et al both generally provided higher HR estimates compared with previous mortality studies. Both studies also used moving averages based on annual mean concentrations at the place of residence. Besides exposure data with 
Hazard Ratio $(95 \% \mathrm{Cl})$

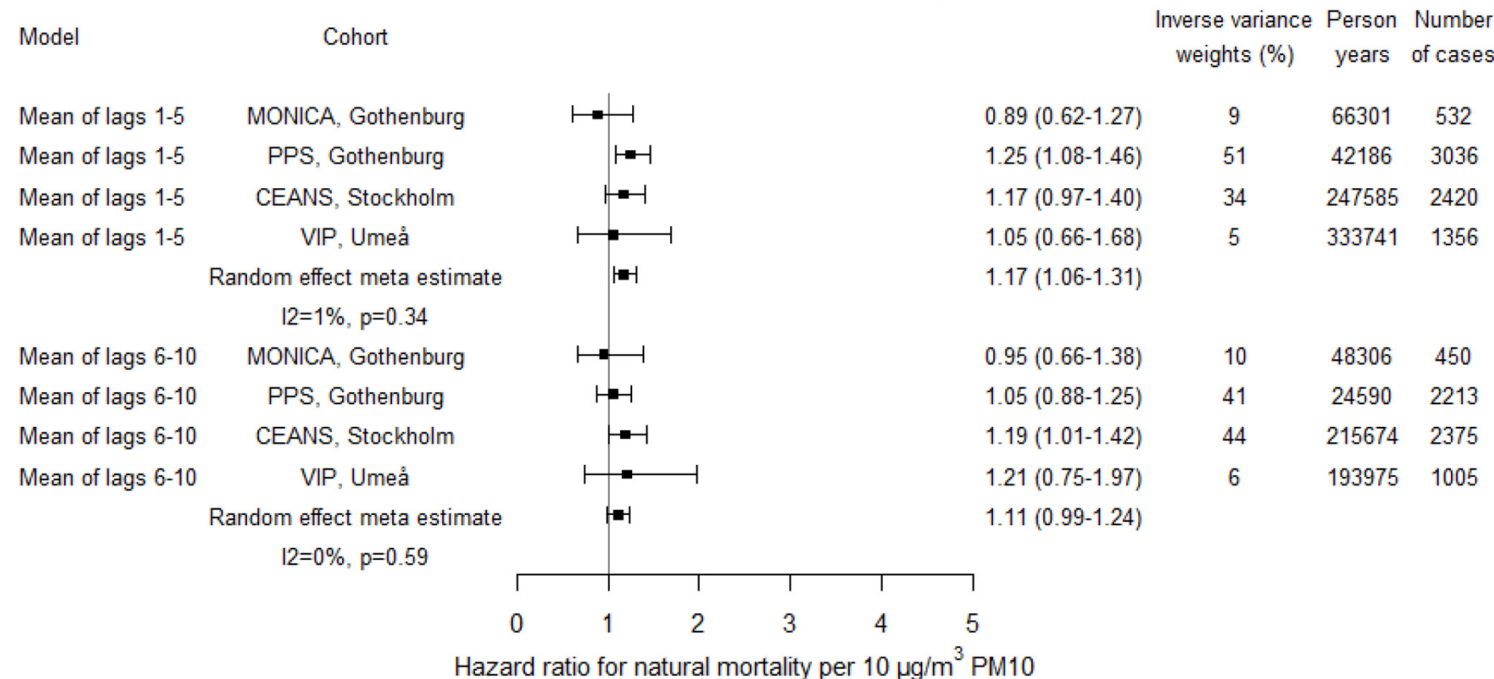

Figure 4 Adjusted HRs for natural mortality associated with PM10 within each cohort and by random effect meta-analyses estimates. Exposures were assessed by moving average residential concentrations within the exposure windows last 5 years and 6-10 years prior. CEANS, Cardiovascular Effects of Air pollution and Noise Study; MONICA, Multinational Monitoring of Trends and Determinants in Cardiovascular Diseases; PM, particulate matter; PPS, Primary Prevention Study; VIP, Västerbotten Intervention Programme.

a high precision such a moving average over relevant time windows may be advantageous compared with residential concentrations at the year of recruitment or a time-weighted average exposure during the follow-up. These two studies also adjusted both for individual data on confounders and neighbourhood-level data on socioeconomics.

\section{Strengths and limitations}

The strength of this study includes the state-of-the-art air pollution modelling used for exposure assessment. Several factors that affect the local dispersion of air pollution particles were considered including meteorological conditions, amount of traffic including vehicle types and speed, which affect exhaust and wear emissions, the width of the street and the height of neighbouring building. This facilitates models with a high spatial resolution providing the ability to estimate an individual's exposure at the residential address. Temporal differences for each address were also accounted for by repeatedly updating the exposure model during the period of follow-up. Our modelled concentrations have showed a good agreement when validated against measured concentrations by monitoring stations in city centres. ${ }^{24}$ Due to uncertainties in data input to the dispersion model,

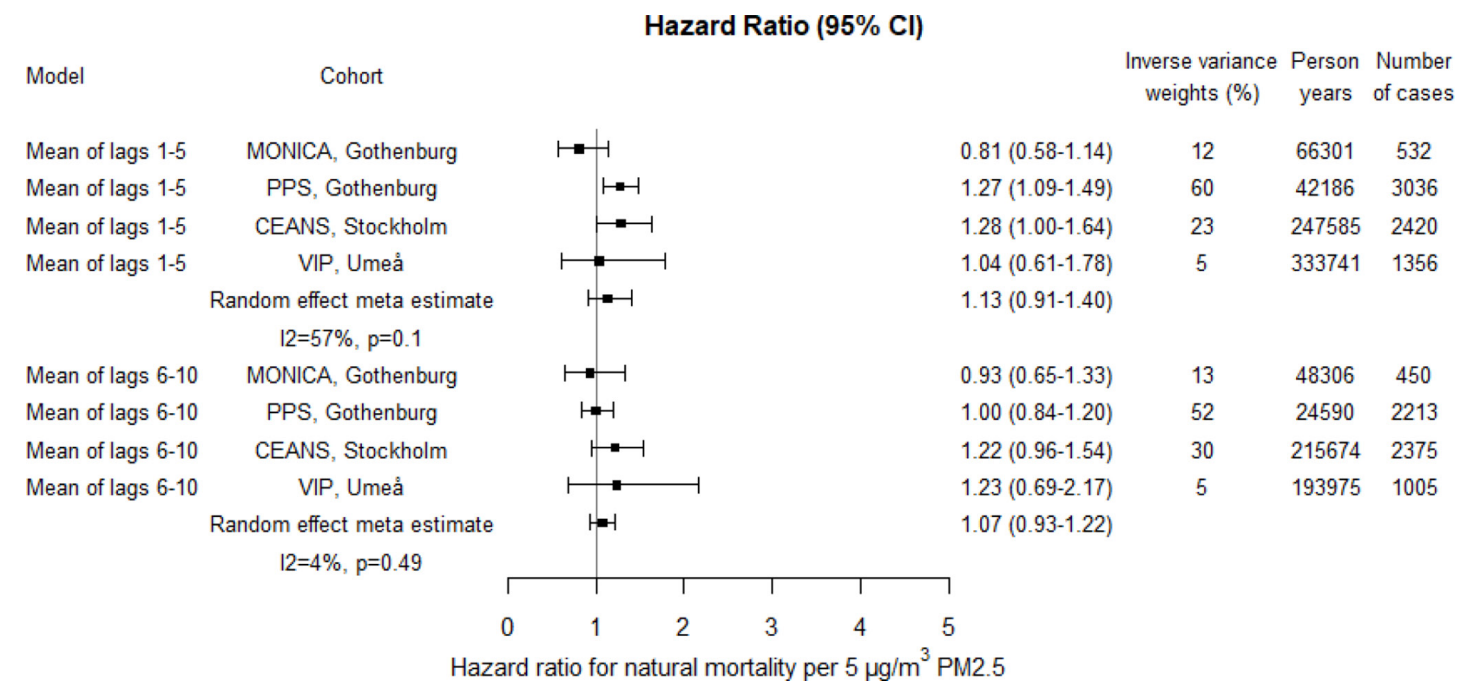

Figure 5 Adjusted HRs for natural mortality associated with PM2.5 within each cohort and by random effect meta-analyses estimates. Exposures were assessed by moving average residential concentrations within the exposure windows last 5 years and 6-10 years prior. CEANS, Cardiovascular Effects of Air pollution and Noise Study; MONICA, Multinational Monitoring of Trends and Determinants in Cardiovascular Diseases; PM, particulate matter; PPS, Primary Prevention Study; VIP, Västerbotten Intervention Programme. 
Hazard Ratio $(95 \% \mathrm{Cl})$

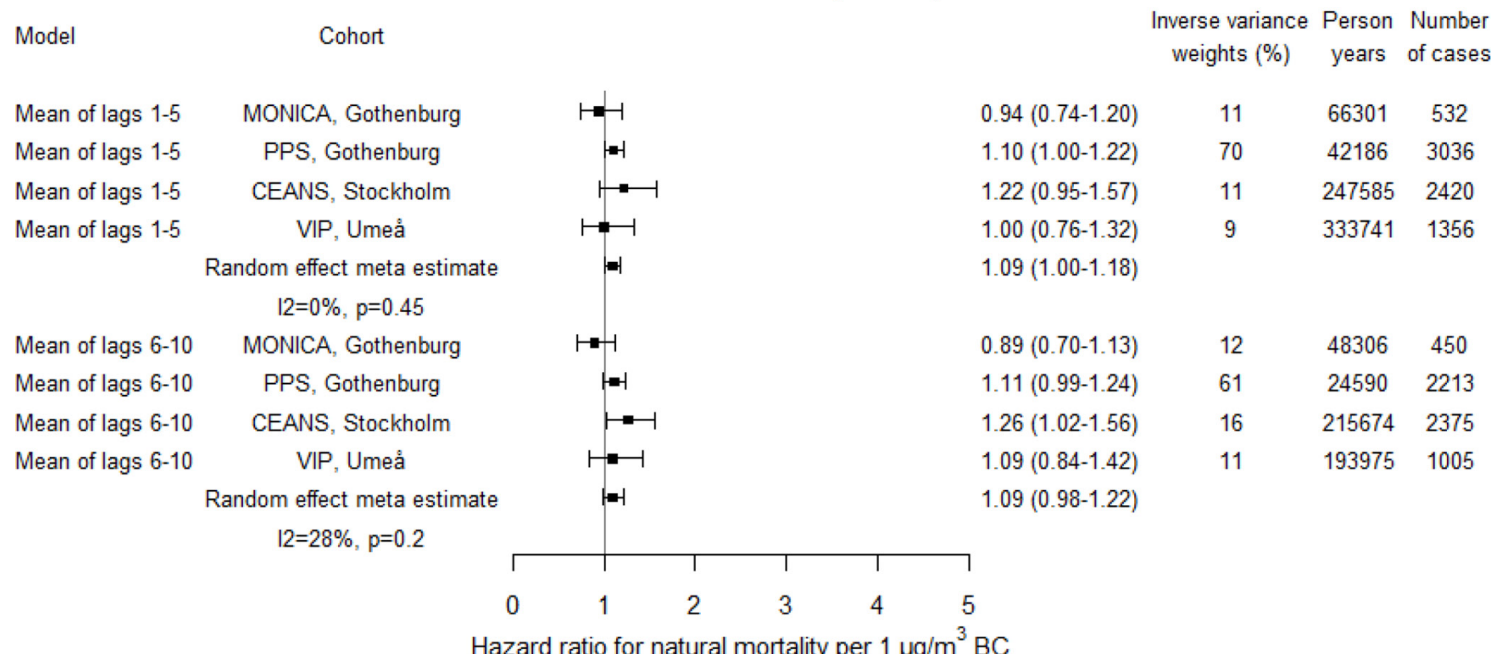

Figure 6 Adjusted HRs for natural mortality associated with black carbon (BC) within each cohort and by random effect metaanalyses estimates. Exposures were assessed by moving average residential concentrations within the exposure windows last 5 years and 6-10 years prior. CEANS, Cardiovascular Effects of Air pollution and Noise Study; MONICA, Multinational Monitoring of Trends and Determinants in Cardiovascular Diseases; PM, particulate matter; PPS, Primary Prevention Study; VIP, Västerbotten Intervention Programme.

and since modelled PM levels at the home address do not equal true personal exposure, exposure misclassifications at the individual level will nevertheless arise. True personal exposure would for instance include indoor particle concentrations at the place of residence, at the workplace and during commuting. During the years of follow-up, there has been a decreasing trend in both total concentrations of PM and age-specific mortality. It was therefore important to adjust for calendar year in the Cox models.

Air pollution gases were not part of our hypothesis and thus not modelled. Studies using nitrogen dioxide
(NO2) and nitrogen oxides as indicators of trafficrelated air pollution have also reported associations with increased risk of premature mortality. ${ }^{2} 38$ Even though there could be an NO2 associated short-term effect on mortality independent of particle matter (eg, Mills et al, ${ }^{39}$ the evidence for long-term effects when controlling for traffic related PM is weaker and exposure to particles is considered as the primary causal determinant of health effects. ${ }^{40}$

As presented above the incidence in ischaemic heart disease and stroke have previously been assessed in relation to particle concentrations on this material. ${ }^{22}$

Hazard Ratio $(95 \% \mathrm{Cl})$

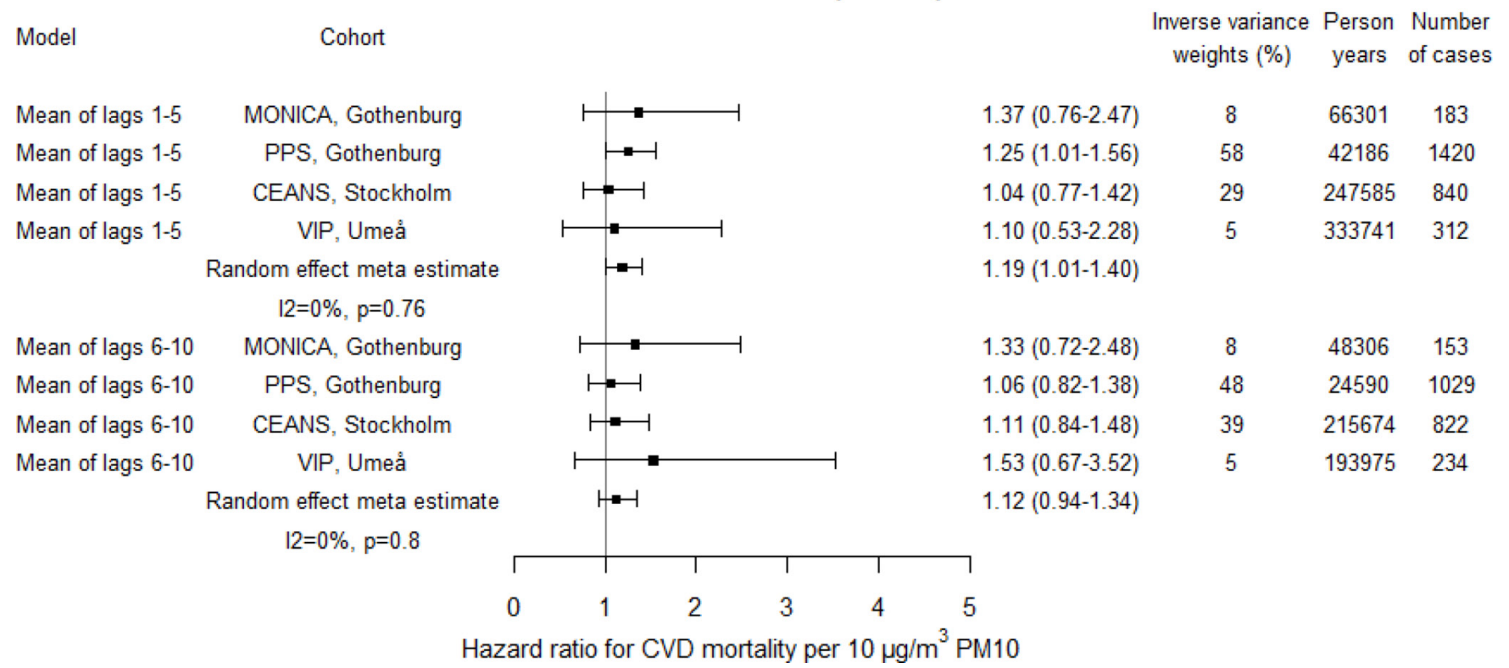

Figure 7 Adjusted HRs for cardiovascular disease (CVD) mortality associated with PM10 within each cohort and by random effect meta-analyses estimates. Exposures were assessed by moving average residential concentrations within the exposure windows last 5 years and 6-10 years prior. CEANS, Cardiovascular Effects of Air pollution and Noise Study; MONICA, Multinational Monitoring of Trends and Determinants in Cardiovascular Diseases; PM, particulate matter; PPS, Primary Prevention Study; VIP, Västerbotten Intervention Programme. 
Hazard Ratio $(95 \% \mathrm{Cl})$

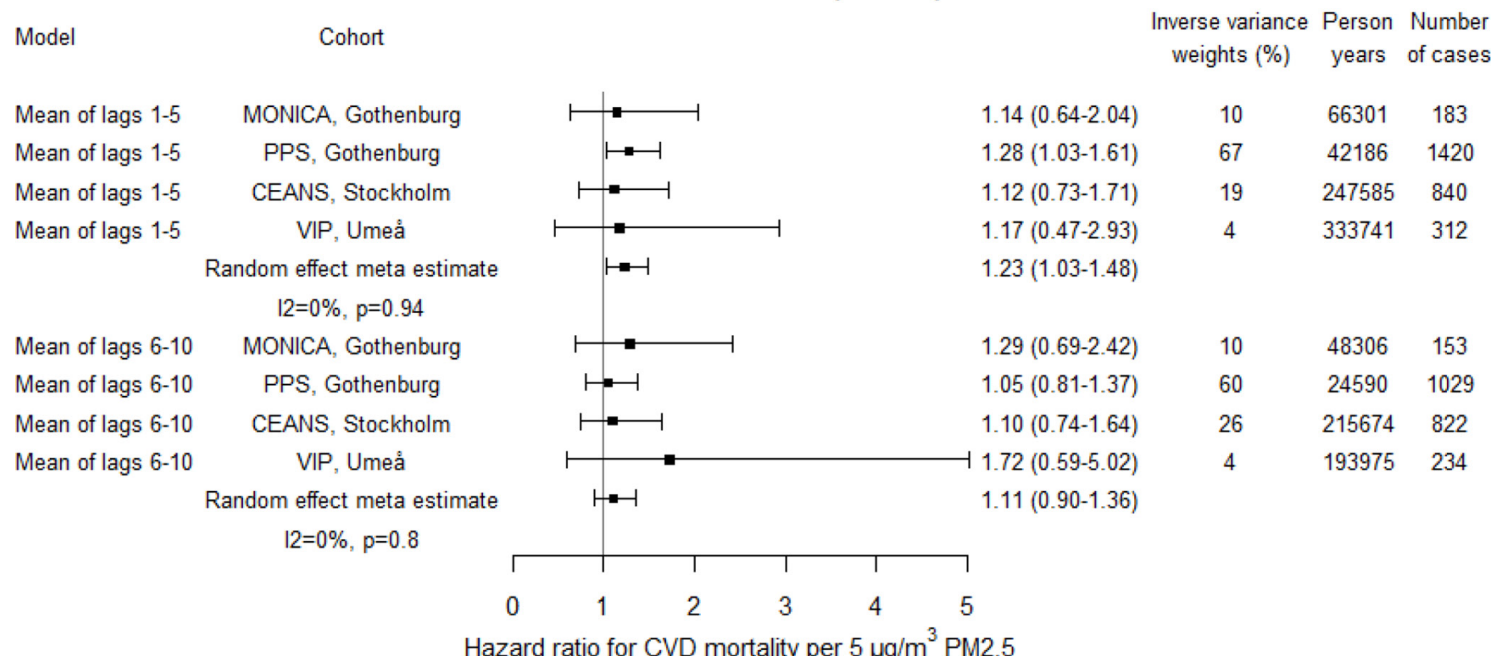

Figure 8 Adjusted HRs for cardiovascular disease (CVD) mortality associated with PM2.5 within each cohort and by random effect meta-analyses estimates. Exposures were assessed by moving average residential concentrations within the exposure windows last 5 years and 6-10 years prior. CEANS, Cardiovascular Effects of Air pollution and Noise Study; MONICA, Multinational Monitoring of Trends and Determinants in Cardiovascular Diseases; PM, particulate matter; PPS, Primary Prevention Study; VIP, Västerbotten Intervention Programme.

If the same hypothesis is repeatably tested on the same material then multiple testing would be an issue, affecting the confidence level of the uncertainty intervals presented for the estimated HRs. On the other hand, results with improvements in exposure data and aggregation with similar cohorts are important to present. Parts of the Stockholm cohorts used for this study were also included in the ESCAPE project estimating the long-term effects on human health of exposure to air pollution in Europe. The period of follow-up differs between these studies, and the exposure modelling and assessment, which were in the
ESCAPE-studies only performed for the year of inclusion and built on land use regression (LUR) models. Also one of the cohorts from Gothenburg (PPS) has been used to study effects of air pollution but with other exposure measures ${ }^{41}$ and outcomes. ${ }^{42}$

Since this is an observational study it was also necessary to adjust for a set of potential confounders, which were prespecified. Mortality outcomes, measures of exposures (PM10, PM2.5 and BC) and time windows (time dependent moving averages over lags $1-5$ and $6-10$, respectively) were also a priori selected. Besides natural mortality associations were assessed with CVD

Hazard Ratio $(95 \% \mathrm{Cl})$

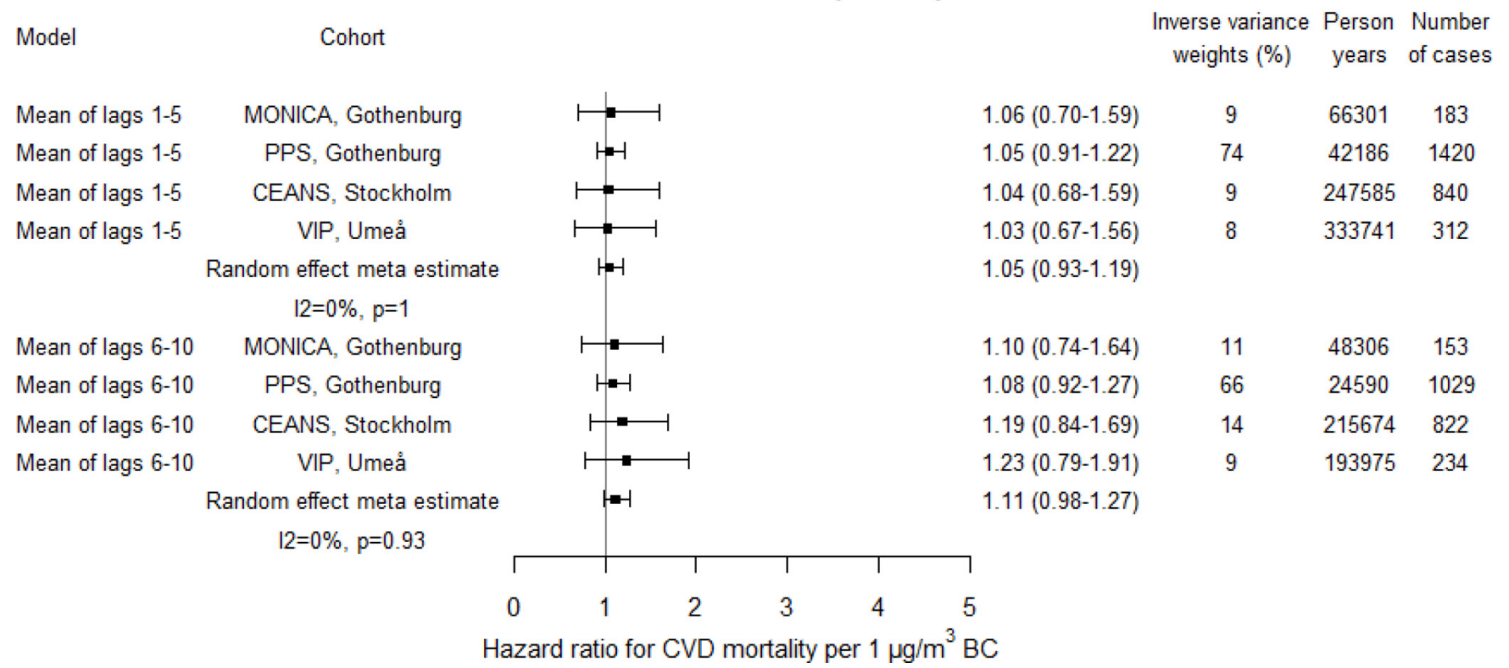

Figure 9 Adjusted HRs for cardiovascular disease (CVD) mortality associated with BC within each cohort and by random effect meta-analyses estimates. Exposures were assessed by moving average residential concentrations within the exposure windows last 5 years and 6-10 years prior. BC, black carbon; CEANS, Cardiovascular Effects of Air pollution and Noise Study; MONICA, Multinational Monitoring of Trends and Determinants in Cardiovascular Diseases; PM, particulate matter; PPS, Primary Prevention Study; VIP, Västerbotten Intervention Programme. 
and three (more) specific causes of death. A limitation that needs to be considered for more exploratory outcomes is that CIs were not constructed to maintain a $95 \%$ familywise error rate. For the interpretation of the results this means that even though the study does not repeatably test the same hypothesis, for instance, in subgroups of participants, it is for causespecific mortality results necessary to consider that the evidence of air pollution effects need to be judged together with other studies. Specifically, for mortality by other causes (other than CVD, lung cancer, respiratory disease and external causes), which has rarely been assessed in relation to air pollution, additional studies are needed. Limitations also include the lack of information on noise exposure and green space near the home address which could be confounders or effect-modifiers of air pollution effects.

Another strength of this study is the large number of cohort participants and ability to adjust for a large set of confounders at both individual and area level, however, information on confounders from questionnaires was only available at baseline. Even though we expect the cohort participants with age ranging from 40 years to have fairly stable lifestyles and habits, such baseline variables may change, for example, due to disease. No clear heterogeneity in associations between cohorts was observed, however, with only four cohorts the test had low statistical power to reject the null hypothesis of homogeneity.

This study additionally contributes with HR estimates between PM and mortality in the lower range of exposure with PM2.5 ranging between 4.0 and $20.4 \mu \mathrm{g} / \mathrm{m}^{3}$ and PM10 ranging between 6.3 and $41.9 \mu \mathrm{g} / \mathrm{m}^{3}$. Even though this is lower than the current EU standards of $25 \mu \mathrm{g} / \mathrm{m}^{3}$ for PM2.5 and (with a few exceptions) lower than $40 \mu \mathrm{g} / \mathrm{m}^{3}$ for PM10, the study found higher relative risks for premature mortality compared with most previous studies even though mean exposures in those studies have been higher.

\section{Conclusions}

This study of four cohorts with relatively low exposures showed increased risks of mortality in association with long-term exposure to PM10, PM2.5 and BC, and thus strongly support long-term air pollution associated effects. Since high-risk increases were observed even at relatively low exposures, the findings are relevant for future decisions concerning air quality policies.

\footnotetext{
Author affiliations

${ }^{1}$ Section of Sustainable Health, Department of Public Health and Clinical Medicine, Umea University, Umeå, Sweden

${ }^{2}$ Occupational and Environmental Medicine, Department of Public Health and Community Medicine, Institute of medicine, Sahlgrenska Academy, University of Gothenburg \& Sahlgrenska University Hospital, Gothenburg, Sweden

${ }^{3}$ Institute of Environmental Medicine, Karolinska Institutet, Stockholm, Sweden

${ }^{4}$ Department of Cardiology, Danderyd Hospital, Stockholm, Sweden

${ }^{5}$ Swedish Meteorological and Hydrological Institute, Norrkoping, Sweden

${ }^{6}$ SLB-analys, Environment and Health Administration, Stockholm, Sweden
}

${ }^{7}$ Family Medicine, Public Health and Clinical Medicine, Umeå University, Umeå, Sweden

${ }^{8}$ Department of Molecular and Clinical Medicine, Institute of Medicine, University of Gothenburg, Sahlgrenska University Hospital, Goteborg, Sweden

${ }^{9}$ Ageing Research Center, Department of Neurobiology, Care Sciences and Society, Karolinska Institutet and Stockholm University, Stockholm, Sweden

${ }^{10}$ Stockholm Gerontology Research Center, Stockholm, Sweden

${ }^{11}$ Centre for Epidemiology and Community Medicine, Stockholm County Council, Stockholm, Sweden

${ }^{12}$ Department of Public Health Science, Karolinska Institutet, Stockholm, Sweden ${ }^{13}$ Department of Medical Epidemiology and Biostatistics, Karolinska Institutet, Stockholm, Sweden

${ }^{14}$ Department of Environmental Science, Stockholm University, Stockholm, Sweden ${ }^{15}$ Centre for Occupational and Environmental Medicine, Region Stockholm, Stockholm, Sweden

Contributors JS performed the meta-analysis and wrote with support from BF the first draft manuscript. JS, EMA, NA and GS conducted the cohort analyses. DS, KE, $L G$ and CJ were responsible for dispersion modelling of particles. PW, AR, DR, KL, $\mathrm{AL}$ and PKEM and were responsible for collection of cohort data. GP, BF, LB, TB, JS, GS, LS, PL, EMA and NA designed the epidemiological study. All authors contributed to the interpretation of the results, finalisation of the manuscript and approved the final manuscript.

Funding This study was funded by the Swedish Environmental Protection Agency as part of the Swedish Clean Air and Climate Research Program (grant NV-06576-13). BF and JS was also supported by NordForsk grant no. 75007. The GOT-MONICA and PPS cohorts were supported by the Swedish Research Council, 2013-5187 (SIMSAM). The SDPP cohort was funded by the Stockholm County Council, the Swedish Research Council, the Swedish Diabetes Association, the Novo Nordisk Scandinavia, and GlaxoSmithKline. The 60Y0 cohort was funded by the Stockholm County Council and the Swedish Research Council. The Swedish Twin Registry is managed by Karolinska Institutet and receives funding through the Swedish Research Council under the grant no. 2017-00641. Data collection in SALT was supported by a grant from the National Institutes of Health $(\mathrm{NIH})$, grant no. 1R01 AG08724. The VIP-Umeå cohort was funded by the Västerbotten County Council. PL was supported by funding from the Swedish Research Council for Health, Working Life and Welfare (FORTE) 2015-00917 and Karolinska Institute's Strategic Research Area in Epidemiology (SF0-EPI). LB was financed by grants from the Swedish state under the agreement between the Swedish government and the county councils: the ALF-agreement (74580).

Competing interests None declared.

Patient consent for publication Not required.

Ethics approval The study was reviewed and approved by the Ethical Review Boards of Gothenburg (references T800-08 and T547-13), Stockholm (reference 2018/2064-32), and Umeå (reference 2015/16-310̈).

Provenance and peer review Not commissioned; externally peer reviewed.

Data availability statement No data are available. No patient involved. The public was also not involved in the design, or conduct, or reporting, or dissemination plans of the research.

Supplemental material This content has been supplied by the author(s). It has not been vetted by BMJ Publishing Group Limited (BMJ) and may not have been peer-reviewed. Any opinions or recommendations discussed are solely those of the author(s) and are not endorsed by BMJ. BMJ disclaims all liability and responsibility arising from any reliance placed on the content. Where the content includes any translated material, BMJ does not warrant the accuracy and reliability of the translations (including but not limited to local regulations, clinical guidelines, terminology, drug names and drug dosages), and is not responsible for any error and/or omissions arising from translation and adaptation or otherwise.

Open access This is an open access article distributed in accordance with the Creative Commons Attribution 4.0 Unported (CC BY 4.0) license, which permits others to copy, redistribute, remix, transform and build upon this work for any purpose, provided the original work is properly cited, a link to the licence is given, and indication of whether changes were made. See: https://creativecommons.org/ licenses/by/4.0\%.

ORCID iD

Johan Nilsson Sommar http://orcid.org/0000-0002-8854-498X 


\section{REFERENCES}

1 Brook RD, Rajagopalan S, Pope CA, et al. Particulate matter air pollution and cardiovascular disease: an update to the scientific statement from the American heart association. Circulation 2010;121:2331-78.

2 Hoek G, Krishnan RM, Beelen R, et al. Long-Term air pollution exposure and cardio- respiratory mortality: a review. Environ Health 2013;12:43.

3 Stanaway JD, Afshin A, Gakidou E, et al. Global, regional, and national comparative risk assessment of 84 behavioural, environmental and occupational, and metabolic risks or clusters of risks for 195 countries and territories, 1990-2017: a systematic analysis for the global burden of disease study 2017. Lancet 2018;392:1923-94.

4 Beelen R, Raaschou-Nielsen O, Stafoggia M, et al. Effects of longterm exposure to air pollution on natural-cause mortality: an analysis of 22 European cohorts within the multicentre escape project. Lancet 2014;383:785-95.

5 Beelen R, Stafoggia M, Raaschou-Nielsen O, et al. Long-Term exposure to air pollution and cardiovascular mortality: an analysis of 22 European cohorts. Epidemiology 2014;25:368-78.

6 Hvidtfeldt UA, Sørensen M, Geels C, et al. Long-term residential exposure to $\mathrm{PM}_{2.5}, \mathrm{PM}_{10}$, black carbon, $\mathrm{NO}_{2}$, and ozone and mortality in a Danish cohort. Environ Int 2019;123:265-72.

7 Dimakopoulou K, Samoli E, Beelen R, et al. Air pollution and nonmalignant respiratory mortality in 16 cohorts within the escape project. Am J Respir Crit Care Med 2014;189:684-96.

8 Luben TJ, Nichols JL, Dutton SJ, et al. A systematic review of cardiovascular emergency department visits, hospital admissions and mortality associated with ambient black carbon. Environ Int 2017;107:154-62.

9 Gan WQ, Koehoorn M, Davies HW, et al. Long-Term exposure to traffic-related air pollution and the risk of coronary heart disease hospitalization and mortality. Environ Health Perspect 2011;119:501-7.

10 Ostro B, Hu J, Goldberg D, et al. Associations of mortality with longterm exposures to fine and ultrafine particles, species and sources: results from the California teachers study cohort. Environ Health Perspect 2015;123:549-56.

11 Ostro B, Lipsett M, Reynolds P, et al. Long-Term exposure to constituents of fine particulate air pollution and mortality: results from the California teachers study. Environ Health Perspect 2010;118:363-9.

12 Baxter LK, Dionisio KL, Burke J, et al. Exposure prediction approaches used in air pollution epidemiology studies: key findings and future recommendations. J Expo Sci Environ Epidemiol 2013;23:654-9.

13 Vodonos A, Awad YA, Schwartz J. The concentration-response between long-term $\mathrm{PM}_{2.5}$ exposure and mortality; A meta-regression approach. Environ Res 2018;166:677-89.

14 Christidis T, Erickson AC, Pappin AJ, et al. Low concentrations of fine particle air pollution and mortality in the Canadian community health survey cohort. Environ Health 2019;18:84

15 Pinault LL, Weichenthal S, Crouse DL, et al. Associations between fine particulate matter and mortality in the 2001 Canadian census health and environment cohort. Environ Res 2017;159:406-15.

16 Pinault L, Tjepkema M, Crouse DL, et al. Risk estimates of mortality attributed to low concentrations of ambient fine particulate matter in the Canadian community health survey cohort. Environ Health 2016;15:18.

17 Shi L, Zanobetti A, Kloog I, et al. Low-Concentration PM2.5 and mortality: estimating acute and chronic effects in a population-based study. Environ Health Perspect 2016;124:46-52.

18 Wilhelmsen L, Berglund G, Elmfeldt D, et al. The multifactor primary prevention trial in Göteborg, Sweden. Eur Heart J 1986;7:279-88.

19 Wilhelmsen L, Johansson S, Rosengren A, et al. Risk factors for cardiovascular disease during the period 1985-1995 in Göteborg, Sweden. The GOT-MONICA project. J Intern Med 1997;242:199-211.

20 WHO MONICA Project Principal Investigators. The world Health organization MONICA Project (monitoring trends and determinants in cardiovascular disease): a major international collaboration. who MONICA project principal Investigators. J Clin Epidemio 1988;41:105-14.
21 Korek MJ, Bellander TD, Lind T, et al. Traffic-Related air pollution exposure and incidence of stroke in four cohorts from Stockholm. J Expo Sci Environ Epidemiol 2015;25:517-23.

22 Ljungman PLS, Andersson N, Stockfelt L, et al. Long-Term exposure to particulate air pollution, black carbon, and their source components in relation to ischemic heart disease and stroke. Environ Health Perspect 2019;127:107012.

23 Norberg M, Wall S, Boman K, et al. The Västerbotten intervention programme: background, design and implications. Glob Health Action 2010;3:4643.

24 Segersson D, Eneroth K, Gidhagen L, et al. Health Impact of $\mathrm{PM}_{10}$, $\mathrm{PM}_{25}$ and Black Carbon Exposure Due to Different Source Sectors in Stockholm, Gothenburg and Umea, Sweden. Int J Environ Res Public Health 2017;14. doi:10.3390/ijerph14070742. [Epub ahead of print: 0707 2017].

25 Berkowicz R. OSPM - A Parameterised Street Pollution Model. Environ Monit Assess 2000;65:323-31.

26 Hausberger S, Rexeis M, Zallinger M. Emission factors from the model PHEM for the HBEFA version 3., Institute for internal combustion engines and thermodynamics, Graz University of technology, 2009.

27 Ilias V, Leonidas N, Zissis S. Methodology for the quantification of road transport PM-Emissions, using emission factors or profiles. deliverable D1.1.2, updated February 2013. TRANSPHORM, 2013. Available: http://www.transphorm.eu/Portals/51/Documents/ Deliverables/New\%20Deliverables/D1.1.2_updated.pdf [Accessed 26 Oct 2018].

28 Denby BR, Sundvor I, Johansson C, et al. A coupled road dust and surface moisture model to predict non-exhaust road traffic induced particle emissions (NORTRIP). Part 2: surface moisture and salt impact modelling. Atmos Environ 2013;81:485-503.

29 Denby BR, Sundvor I, Johansson C, et al. A coupled road dust and surface moisture model to predict non-exhaust road traffic induced particle emissions (NORTRIP). Part 1: road dust loading and suspension modelling. Atmos Environ 2013;77:283-300.

30 Omstedt G, Bringfelt B, Johansson C. A model for vehicle-induced non-tailpipe emissions of particles along Swedish roads. Atmos Environ 2005;39:6088-97.

31 Jalkanen J-P, Johansson L, Kukkonen J, et al. Extension of an assessment model of SHIP traffic exhaust emissions for particulate matter and carbon monoxide. Atmos Chem Phys 2012;12:2641-59.

32 Forsberg $\mathrm{B}$, Hansson $\mathrm{H}-\mathrm{C}$, Johansson $\mathrm{C}$, et al. Comparative health impact assessment of local and regional particulate air pollutants in Scandinavia. Ambio 2005;34:11-19.

33 DerSimonian R, Laird N. Meta-Analysis in clinical trials. Control Clin Trials 1986;7:177-88

34 Cesaroni G, Badaloni C, Gariazzo C, et al. Long-Term exposure to urban air pollution and mortality in a cohort of more than a million adults in Rome. Environ Health Perspect 2013;121:324-31.

35 Hamra GB, Guha N, Cohen A, et al. Outdoor particulate matter exposure and lung cancer: a systematic review and meta-analysis. Environ Health Perspect 2014;122:906-11.

36 Raaschou-Nielsen O, Andersen ZJ, Beelen R, et al. Air pollution and lung cancer incidence in 17 European cohorts: prospective analyses from the European study of cohorts for air pollution effects (escape). Lancet Oncol 2013;14:813-22.

37 Lefler JS, Higbee JD, Burnett RT, et al. Air pollution and mortality in a large, representative U.S. cohort: multiple-pollutant analyses, and spatial and temporal decompositions. Environ Health 2019;18:101.

38 Atkinson RW, Butland BK, Anderson HR, et al. Long-Term concentrations of nitrogen dioxide and mortality: a meta-analysis of cohort studies. Epidemiology 2018;29:460-72.

39 Mills IC, Atkinson RW, Anderson HR, et al. Distinguishing the associations between daily mortality and hospital admissions and nitrogen dioxide from those of particulate matter: a systematic review and meta-analysis. BMJ Open 2016;6:e010751.

40 WHO. Review of evidence on health aspects of air pollution REVIHAAP Project: Technical Report. Copenhagen, 2013.

41 Stockfelt L, Andersson EM, Molnár P, et al. Long term effects of residential $\mathrm{NO}(\mathrm{x})$ exposure on total and cause-specific mortality and incidence of myocardial infarction in a Swedish cohort. Environ Res 2015;142:197-206.

42 Andersson EM, Ögren M, Molnár P, et al. Road traffic noise, air pollution and cardiovascular events in a Swedish cohort. Environ Res 2020;185:109446. 